\title{
Maintaining Symbiotic Homeostasis: How Do Plants Engage With Beneficial Microorganisms While at the Same Time Restricting Pathogens?
}

\author{
David Thoms, ${ }^{1,2}$ Yan Liang, ${ }^{3}$ and Cara H. Haney ${ }^{1,2,+}$ \\ ${ }^{1}$ Department of Microbiology and Immunology, The University of British Columbia, Vancouver, V6T 1Z3 Canada \\ ${ }^{2}$ Michael Smith Laboratories, The University of British Columbia, Vancouver, V6T 1 Z4 Canada \\ ${ }^{3}$ College of Agriculture and Biotechnology, Zhejiang University, Hangzhou 310058, China
}

Accepted 1 February 2021.

\begin{abstract}
That plants recruit beneficial microbes while simultaneously restricting pathogens is critical to their survival. Plants must exclude pathogens; however, most land plants are able to form mutualistic symbioses with arbuscular mycorrhizal fungi. Plants also associate with the complex microbial communities that form the microbiome. The outcome of each symbiotic interaction-whether a specific microbe is pathogenic, commensal, or mutualistic-relies on the specific interplay of host and microbial genetics and the environment. Here, we discuss how plants use metabolites as a gate to select which microbes can be symbiotic. Once present, we discuss how plants integrate multiple inputs to initiate programs of immunity or mutualistic symbiosis and how this paradigm may be expanded to the microbiome. Finally, we discuss how environmental signals are integrated with immunity to fine-tune a thermostat that determines whether a plant engages in mutualism, resistance to pathogens, and shapes associations with the microbiome. Collectively, we propose that the plant immune thermostat is set to select for and tolerate a largely nonharmful microbiome while receptor-mediated decision making allows plants to detect and dynamically respond to the presence of potential pathogens or mutualists.
\end{abstract}

Keywords: elicitors, environmental signals, MAMPs, mutualistic symbiosis, PAMPs, plant responses to pathogens, secondary metabolism

Plants can fix carbon and thus provide microbes with a habitat enriched in sugars relative to the environment. As a result, living in association with a plant presents an opportunity for microbes to access nutrients that are otherwise limited. To

${ }^{\dagger}$ Corresponding author: C. H. Haney; cara.haney@msl.ubc.ca

Funding: This work was supported by a Tier 2 Canada Research Chair awarded to C. H. Haney, a National Science Foundation Postdoctoral Fellowship in Biological Sciences (award number 2010946) awarded to D. Thom, and National Natural Science Foundation of China (31770263) awarded to Y. Liang.

The author(s) declare no conflict of interest.

$($ (1) $\circledast \Theta$ Copyright $\odot 2021$ The Author(s). This is an open access article distributed under the CC BY-NC-ND 4.0 International license. survive, plants must exclude microbes, including fungi, bacteria, and viruses, that, given the opportunity, would parasitize plants for carbon and other nutrients. However, most land plants are able to form mutualistic symbioses with arbuscular mycorrhizal (AM) fungi, while others associate with beneficial nitrogen-fixing rhizobia or ectomycorrhizal fungi and manage to avoid being parasitized by these microbes. Plants also form stable associations with thousands of microbial taxa that make up the microbiome (Müller et al. 2016), which can protect plants from pathogens (Berendsen et al. 2012) and help plants access nitrogen, phosphorous, iron, and micronutrients (Hacquard et al. 2015). How plants recruit beneficial microbes while simultaneously restricting pathogens is a fundamental question in the molecular-plant microbe interactions field and was nominated as one of the top 10 unanswered questions at the 18th IS-MPMI Congress in 2019 (Harris et al. 2020).

All symbiotic microbes, be they mutualistic, pathogenic, or commensal, must be able to utilize host nutrients and evade or suppress host immunity. Once microbes are present, plants must decide to tolerate their presence, engage in mutualistic symbiosis, or mount an immune response. The mechanisms that govern a subset of symbiotic interactions, such as the mutualistic association of nitrogen-fixing rhizobial bacteria with legumes and immunity of the reference plant Arabidopsis to bacterial pathogens like Pseudomonas syringae, have been relatively well-studied. Both immunity to pathogens and mutualism require recognition of microbial molecules resulting in symbiosis or defense. In rhizobia-legume interactions, plants recognize specific microbial chemical signals, which leads to mutualistic symbiosis. Plant recognition of pathogens can lead to a robust immune response and restriction of microbial growth. Studying the mechanisms that determine the outcomes of a few model symbioses have provided a framework for molecular-plant microbe interactions that have informed our understanding across plant hosts and symbionts.

Beyond intimately coevolved mutualistic or pathogenic associations, plants provide a habitat for thousands of microbiota. Unlike rhizobia-legume symbioses or plant-AM symbiosis, in which extensive coevolution has shaped symbiotic outcomes (Denison and Kiers 2011), the life history of plant-microbiome associations is more poorly understood. While there is evidence for a host-driven genetic component to microbiome community structure (Bulgarelli et al. 2012; Haney et al. 2015; Schlaeppi et al. 2014), it is not entirely clear whether plant-microbiome interactions have the same level of specificity and could be 
governed by similar principles as well-studied mutualistic symbioses and pathogens, or whether there are distinct principles that shape plant-microbiome association.

In this review, we discuss three stages in symbiotic engagement, each with the potential to select for or restrict potential mutualists or pathogens (Fig. 1). These include i) metabolic gating whereby microbial access to plants is restricted through plant production of selective metabolites, ii) dual receptor recognition in which congruent signals received by multiple receptors initiate a robust and specific program of symbiosis or immunity, and iii) integration of environmental signals with immune homeostasis to fine-tune decision making in symbiosis. We primarily focus on how these principles shape interactions in the rhizosphere, in which the most is known about mutualists and commensals, although the majority of immunity work has focused on leaves. Collectively, these concepts provide a paradigm for understanding how plants may engage with beneficial microbes while restricting pathogens.

\section{METABOLIC GATING: THE CHEMISTRY OF SELECTING FOR SYMBIONTS}

Plants offer a chemically and nutritionally distinct environment relative to the soil and air that surround them. The rhizosphere may be enriched in central metabolites, including derivatives of plant photosynthate, along with diverse plantderived specialized metabolites (Hacquard et al. 2015; Hartmann et al. 2008). Plants thus have the potential to screen and select for specific symbiotic associations through central and specialized metabolites by secreting i) nutrients that only some microbes can use, ii) antimicrobial compounds that are toxic to some but not all microbes, and iii) signals that attract specific microbes (Fig. 1A). Given the richness of plant metabolites and diversity across plant species (Owen et al. 2017), plant chemical profiles have the potential to provide a high degree of symbiotic specificity.

The rhizosphere is a nutritionally complex environment, and we are only just beginning to reveal the nutrients present and the consequences for symbiotic associations. Chemicals in root exudates, such as citric acid, malic acid, and fumaric acid, have been shown to play roles in recruiting beneficial bacteria (Rudrappa et al. 2008). Genomic and forward genetic screening in beneficial Pseudomonas spp. has shown that auxotrophy for specific amino acids reduces fitness in the rhizosphere, indicating that ability to use host nutrients may be a determining factor in symbiotic associations (Cheng et al. 2017; Cole et al. 2017; Liu et al. 2018). These observations indicate that the presence of specific host nutrient sources may be a major determinant of which microbes can initiate symbiosis.

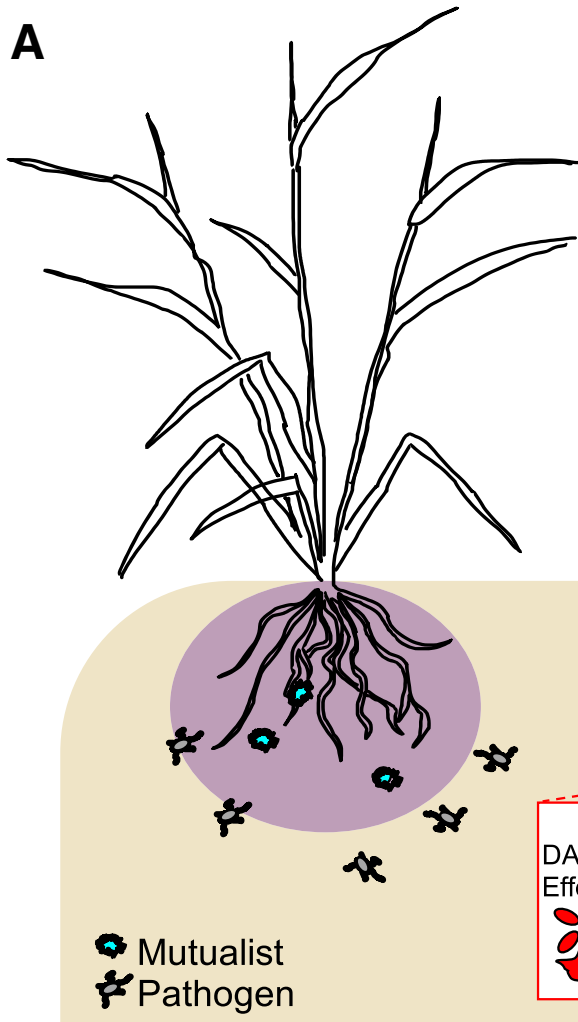

Selecting with metabolites
B

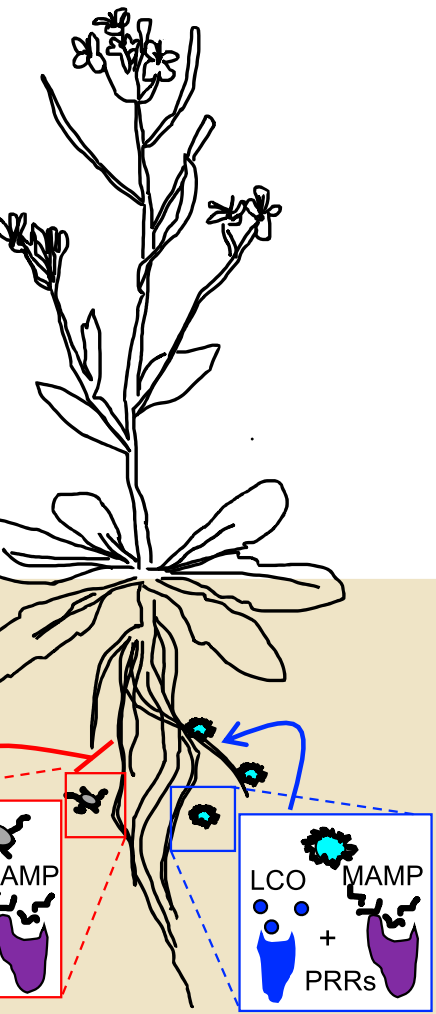

Dual receptor

recognition
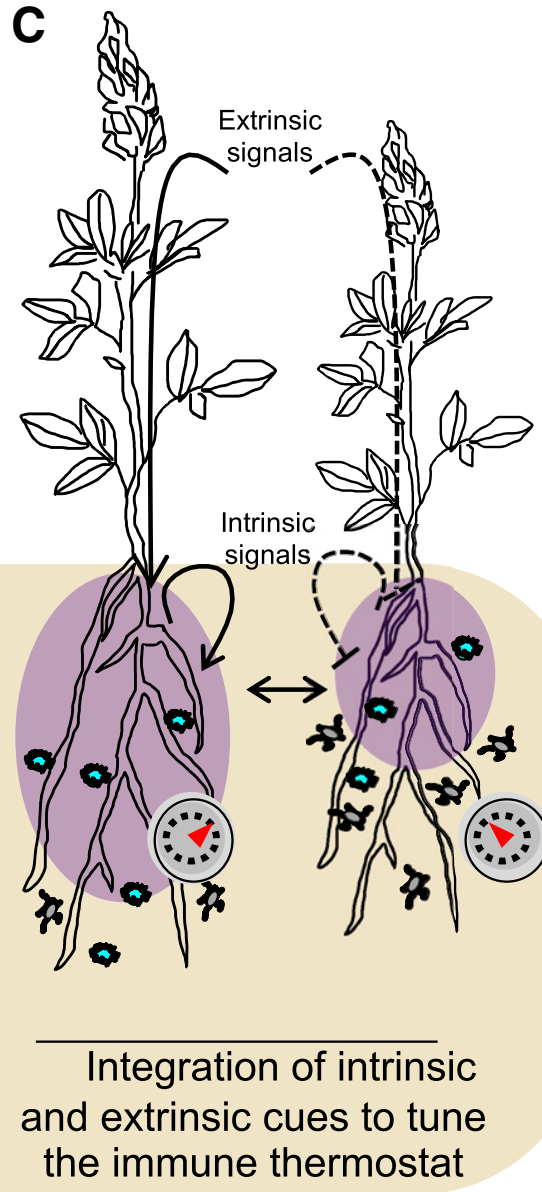

Fig. 1. Mechanisms of symbiotic engagement. This review discusses three principles by which plants may select for or restrict potential mutualists or pathogens. A, Plants use selective metabolites (purple) to recruit or select for beneficial microbes (blue) and select against pathogens (gray). B, Dual receptor recognition allows for precisely distinguishing potential pathogens or mutualists prior to energy investment in an immune or symbiotic response. Microbeassociated molecular patterns (MAMPs) are common between pathogens and mutualists and so are not sufficient for a plant to determine whether a microbe is friend or foe; however, MAMPs can provide information about the identity of a microbe. Coupling perception of MAMPs with lipochitooligosaccharides (LCOs), effectors, or damage-associated molecular patterns (DAMPs) has the potential to trigger a strong and specific immunity or symbiotic program. C, Integration of intrinsic and extrinsic signals with immune homeostasis allows plants to fine-tune decision making in symbiosis and dynamically shape symbiotic interactions over a plant's life. This may allow for fine-tuning of microbiome community structure as well as changing a threshold for strong immunity and symbiosis responses. 
Specialized metabolites may also play a role in selecting for symbiotic associations and may explain host specificity. Triterpenes, a large and diverse group of plant specialized metabolites, mediate the establishment of the microbiome both by promoting and restricting growth of specific microbial taxa (Huang et al. 2019). Salicylic acid is a plant hormone that affects plant immunity and microbiome structure, potentially, in part, by acting as a metabolite for specific microbes (Lebeis et al. 2015). Complex or species-specific nutrients may play a role in selecting for highly adapted microbes and may contribute to host specificity in symbiotic associations.

Similarly, there are potentially thousands of antimicrobial compounds produced by plants, and we have only seen the tip of the iceberg in understanding how these molecules exclude some microbes while allowing the proliferation of others. Plant-derived coumarins have antimicrobial activity against some, but not microbiota, and, as a result, can directly shape the plant microbiome (Voges et al. 2019). Similarly, canavanine is a toxic structural mimic of arginine and is produced by certain legumes; rhizobia have evolved resistance to canavanine, allowing for their proliferation in the rhizosphere (Cai et al. 2009). These examples suggest that plants may be able to use metabolites to select for specific adapted microbes while excluding others.

Metabolites secreted by plants can also signal the presence of a symbiont-friendly host. Nitrogen-fixing rhizobia can sense plant flavonoids through binding of the bacterial regulator of Nod factor biosynthesis NodD (Fisher and Long 1992). The plant hormone strigolactone can trigger AM fungal spore germination and thus signals the presence of a potential plant host (Akiyama and Hayashi 2006; Besserer et al. 2006). Commensals may also use the presence of plant metabolites including polyamines (Liu et al. 2018), amino acids, organic acids, or sugars (Sasse et al. 2018) to signal the presence of a plant host. Secretion of positive signals may provide plants with a way to call to only beneficial microbes among diverse soil microbiota.

Estimates are that plants may produce hundreds of thousands of compounds, a small fraction of which have been characterized (Jacobowitz and Weng 2020). As a result, the metabolic potential of plants could be a major determinant of host specificity and actively or passively shape host-symbiotic interactions. Characterizing the diversity of plant metabolites will undoubtedly reveal the role that these compounds play in how plants select for beneficial microbes while restricting pathogens.

\section{FINE-TUNING RECOGNITION: INTEGRATION OF DUAL SIGNALS TO DISTINGUISH FRIEND FROM FOE}

Once a microbe has located a host in which it can compete for nutrients and survive the onslaught of host-derived antimicrobials, the microbe has the potential to become symbiotic. Once a microbe is symbiotic, the exchange of molecular signals, combined with host and microbial genetic potential, helps plants determine whether a microbe is a friend or foe (Zipfel and Oldroyd 2017). However, many of the potential molecular signals do not necessarily distinguish pathogen from commensals. As a result, perception and integration of multiple cues is required to initiate a successful immunity or symbiosis program (Figs. 1B and 2).

Plant genomes encode a staggering suite of receptors, including hundreds of predicted membrane-associated pattern recognition receptors (PRRs) (Zipfel 2014) and cytoplasmic Nod-like receptors (NLRs) (Monteiro and Nishimura 2018). This receptor diversification has been proposed to function in expanding innate immunity, although the ligands for only a very small portion have been identified (Zipfel 2014). Specific PRRs are required for symbiosis or function in pattern triggered immunity (PTI) and recognize conserved microbe-associated molecular patterns (MAMPs) like chitin, flagellin, and peptidoglycan (Zipfel and Oldroyd 2017). Collectively, these observations suggest that plants have the receptor diversity to distinguish a vast number of potential symbionts.

\section{Recognizing pathogens.}

Because many MAMPs are conserved in both pathogenic and nonpathogenic microbes, recognition by a combination of receptors may be necessary to initiate a robust immune response (Jones and Dangl 2006). In plant immunity, the long-standing zig-zag paradigm proposes that recognition of a MAMP may lead to a weak PTI response, while recognition of a MAMP and an effector protein might lead to robust effector-triggered immunity (ETI) (Jones and Dangl 2006). More recent evidence supports that PTI and ETI are not distinct pathways but rather converge to trigger a robust antibacterial immune response (Ngou et al. 2020; Yuan et al. 2020). While effector recognition increases expression of several key PTI-associated genes, effector recognition alone does not seem to provide resistance against bacterial pathogens unless paired with MAMP perception (Yuan et al. 2020). Effectors and, perhaps, damageassociated molecular patterns (DAMPs) may generate a more robust immune response by increasing gene expression of components involved in PTI (Yuan et al. 2020; Zhou et al. 2020). For example, effector perception enhances RBOHD expression, while flg22 induces a posttranslational increase in RBOHD activity that synergistically increases ROS accumulation (Kadota et al. 2014; Li et al. 2014; Yuan et al. 2020). Just as signaling through cell surface PRRs depends upon the intracellular receptors of ETI for resistance against effectorcontaining bacterial pathogens, we discuss how integration of multiple signals may allow for initiation of symbiosis with mutualists or an immune response against members of the microbiota. It is worth noting that, as plant immunity has primarily been studied in leaves, it is possible that distinct paradigms contribute to immunity in the rhizosphere (Chuberre et al. 2018; Millet et al. 2010).

\section{Recognizing mutualists.}

Recognition by multiple receptors and integration of multiple symbiotic and immunity signals is required for establishment of mutualistic symbiosis. Rhizobia-legume symbiosis is initiated when rhizobia secrete lipochitooligosaccharides (LCOs), referred to as Nod factors, that consist of a short-chain chitin backbone with different substitutions (D'Haeze and Holsters 2002; Gough and Cullimore 2011). Interestingly, many legumes have multiple LysM receptors that are required to recognize the correct Nod factor and, in some cases, regulate parallel signaling pathways (Limpens et al. 2003). For instance, Medicago truncatula NFP and LYK3 recognize the nonreducing and reducing ends of Nod factor, respectively (Smit et al. 2007), and initiate signaling pathways that regulate calcium spiking and nodule formation (NFP) and infection thread initiation (LYK3) (Jones et al. 2007). By requiring successful recognition by multiple receptors, plants can use multiple check points to ensure the presence of the correct symbiont and exclude potential cheaters.

Nod factor is not the only microbial signal required to initiate rhizobia-legume symbiosis; other conserved MAMPs play roles in establishing beneficial associations, potentially by preventing overgrowth or symbiotic mimicry. Rhizobial exopolysaccharides (EPSs) are polysaccharide polymers secreted into the surrounding environment and are required for the formation of infection threads during nodulation (Denny 1995; Milling 
et al. 2011; Robertsen et al. 1981; Saile et al. 1997). A LysM receptor-like kinase identified in Lotus japonicus is required for symbiosis and has been implicated in perception of rhizobial EPSs (Kawaharada et al. 2015). Lipopolysaccharides (LPSs) are major components of the bacterial outer membranes that comprise lipid A, a core oligosaccharide, and an $\mathrm{O}$-antigen polysaccharide (Becker et al. 2005; Erridge et al. 2002). Nodulation does not occur when plants are inoculated with mutants defective in LPS synthesis or altered LSP structure, indicating that LPSs might also act as signaling molecules for the establishment of symbiotic relationships (Bourassa et al. 2017) or that the wrong LPS might trigger immunity leading to nonfunctional nodules. Collectively, this supports that multiple positive signals or positive signals without negative signals are required to initiate symbiosis.

In addition to rhizobial Nod factor, LCOs are produced by $\mathrm{AM}$ and ectomycorrhizal fungi during the establishment of symbiosis (Cope et al. 2019; Maillet et al. 2011). However, it was recently reported that LCOs are also produced by nonsymbiotic and even pathogenic fungi (Rush et al. 2020), suggesting that LCOs might have other roles beyond symbiotic signals. Indeed, LCOs suppress immunity signaling, potentially independently of symbiotic signaling (Feng et al. 2019; Liang et al. 2013). Taken together, these findings suggest that either plants have evolved distinct receptors and signaling pathways for symbiosis and immunity or that there may be overlap in perception of mutualists and pathogens.

Emergent evidence supports that initiation of mutualistic symbiosis may involve inputs from overlapping immunity and symbiosis pathways. LysM receptors recognize diverse $\mathrm{N}$ acetyl glucosamine polymers, including chitin and peptidoglycan, the major cell-wall components of fungi and bacteria, respectively (Zipfel and Oldroyd 2017). Chitin and peptidoglycan are recognized as MAMPs by plants, leading to the induction of innate immunity. Studies on AM and chitin recognition in rice led to an interaction model in which a LysM receptor-like kinase, OsCERK1, plays dual roles in immunity and symbiosis (He et al. 2019; Miyata et al. 2014). OsCERK1 does not have high affinity for binding chitin oligosaccharides; instead, other members of the LysM receptor-like protein kinase family distinguish the ligands according to the length of chitin oligosaccharides and, then, transduce signals via the formation of complexes with OsCERK1 (Hayafune et al. 2014; $\mathrm{He}$ et al. 2019). Allele variation in OsCERK1 contributes to the efficiency of AM colonization (Huang et al. 2020). In contrast, OsCERK1 orthologs in legumes underwent several rounds of gene duplication, and one copy maintains a similar dual function in AM and immunity, but a paralogous copy might have evolved leading to neofunctionalization for Nod factor perception (Bozsoki et al. 2017; Gibelin-Viala et al. 2019; Leppyanen et al. 2017). Interestingly, these OsCERK1 orthologs in legumes might have higher affinity binding to allow for discriminating between chitin oligosaccharides and Nod factor (Bozsoki et al. 2020). Given that fungal and bacterial symbionts produce both symbiosis- and immunity-inducing signals, it is very likely that hosts must possess complex logic gates to determine whether they should initiate symbiosis or immunity and many pathways are integrated to control the final outcome.

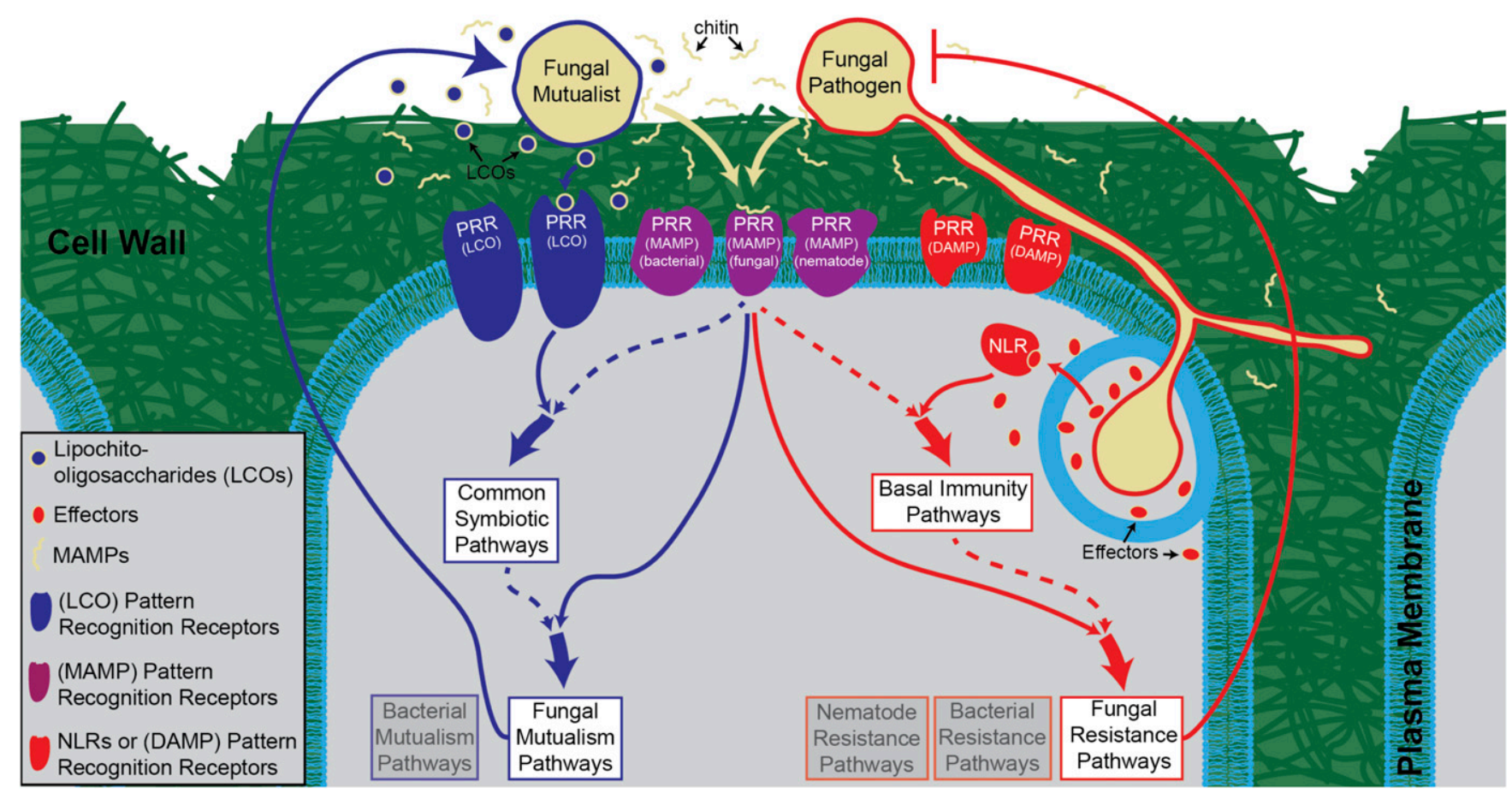

Fig. 2. Multiple receptor inputs contribute to specific and robust immunity and symbiosis responses. To decide whether to engage in immunity or symbiosis, a plant must identify the type of microbe it is interacting with and determine whether that microbe is mutualistic or pathogenic. Robust activation of a specific pathway depends on the combined input of microbe-associated molecular patterns (MAMPs) and one or more lifestyle associated factor (e.g., damageassociated molecular patterns (DAMPs), effectors, lipochitooligosaccharides [LCOs]). In this example, chitin informs the plant that the symbiont is a fungus, and LCOs or effectors inform the plant whether it is a mutualist (blue components and arrows) or pathogenic (red components and arrows). The central boxes represent basal immunity pathways and common symbiotic pathways, which include the respective signaling cascades, posttranslational modifications, and gene induction required for initiation of an immune or mutualistic response. At the bottom are the microbe-specific responses for resistance against or mutualism with a specific type of microbe. Activated pathways are indicated by white boxes and inactive pathways are shown in gray. Dotted lines indicate weak signaling and activation, while solid lines reflect stronger interactions. Wide arrows represent either a synergistic or additive response. PRR = pattern recognition receptor, NLR $=$ Nod-like receptor. 


\section{Recognizing microbiota.}

The plant immune system clearly plays a role in shaping the microbiome, and members of the microbiota must evade or suppress immunity in order to survive (Teixeira et al. 2019). Yet, how plants might initiate symbiotic or immunity programs against the thousands of members of the microbiome is less clear. In many cases, plants cannot distinguish MAMPs from beneficial vs. pathogenic microbes. While certain mutualists like rhizobium may have distinct or cloaked MAMPs that are not recognized by plants (Jones et al. 2007), other commensals, like P. fluorescens, have MAMPs that are similarly antigenic as those in their pathogenic relatives (Yu et al. 2019). Most rhizosphere microbiome members do not have known effectors that trigger ETI, nor do they encode positive signals, like Nod factor, that might trigger a symbiotic program. As a result, it is possible that plants may simply tolerate the diverse microbes that are able to survive in close association without causing any major harm or offering clear benefits.

In the event members of the microbiota do cause harm to the host, an intriguing emergent possibility is that plants may use cellular damage through plant-derived DAMPs (Hander et al. 2019; Poncini et al. 2017; Zhou et al. 2020) to exclude certain members of the microbiome. DAMPs are intracellular plant molecules that can induce an immune response only when bound to their corresponding extracellular receptors (Choi and Klessig 2016). To date, a wide array of immunomodulatory DAMPs (e.g., plant elicitor peptides [Peps], PAMP-induced secreted peptides, extracellular ATP, and oligogalacturonides) and their respective receptors (e.g., PEPRs, RLK7, P2K1 and P2K2, and WAK1) have been identified in Arabidopsis (Brutus et al. 2010; Hou et al. 2014; Jewell et al. 2019; Pham et al. 2020; Yamaguchi et al. 2010), indicating that plants have the potential to identify the diverse types of damage that microbes might elicit.

When combined with MAMP perception, cell damage has the potential to elicit a robust and highly specific local immune response (Zhou et al. 2020). In contrast, cellular damage or the flagellin peptide flg22 alone elicits a more limited immune response in roots (Zhou et al. 2020). In the presence of flg22, laser ablation of a single root cell induces a flg22-receptor (FLS2)-dependent immune response in adjacent cells but not in distal root cells, indicating that plants elicit a localized response upon sensing the co-occurrence of MAMPs and damage (Zhou et al. 2020). This raises an interesting question of whether plants could use a targeted immune response to actively inhibit bacteria that damage plant cells while leaving bacteria associated with adjacent nondamaged cells intact. Whether plants can use damage to distinguish and select for beneficial over harmful bacteria is currently unknown.

The type of damage induced by a microbe may depend on the lifestyle of the assailant and, when combined with MAMP signals, may provide clues as to the identity of the invading organism. For example, the cell wall-degrading enzymes common in fungi and bacteria may generate vastly more cell wall-degradation compounds (e.g., cellobiose, oligogalacturonides) than nematodes (Berlemont and Martiny 2013; Saravanakumar et al. 2018, 2016). In contrast, the piercing mouthparts of nematodes could release vastly more intracellular DAMPs (such as Peps) than bacteria or fungi (Lee et al. 2018; Klauser et al. 2015; Zhang and Gleason 2020). This suggests that simultaneous perception of a DAMP and MAMP generated by the same microbe could signal a more tenacious invader that requires a more specific and robust immune response. In support of this, cellobiose cotreated with chitin leads to relatively higher induction of WRKY3O than cellobiose cotreated with flg22 (Souza et al. 2017). Pep1 can induce a plant immune response that impairs plant parasitic nematode reproduction (Zhang and Gleason 2020); yet, Pep1-triggered immunity seems to have little overlap with signaling pathways commonly attributed to bacterial defense (Zhang and Gleason 2020; Zhou et al. 2020). These data support an intriguing possibility whereby combined DAMP and MAMP perception could provide dual inputs to allow for plants to fine-tune a localized immune response against the specific invader while leaving the majority of the members of the microbiome unharmed.

\section{SETTING THE THERMOSTAT: PLANT IMMUNE HOMEOSTASIS}

In animals, the immune system only develops properly in the presence of commensals. Germ-free mice have highly altered gut architecture and lack normal immune function (Gallo and Hooper 2012). In contrast, most studies on the plant immune system have been performed with the reference plant Arabidopsis under highly controlled conditions comparing the plant immune response to a microbe, MAMP, or DAMP, to an oftenaxenic baseline. As a result, we have a much better sense of the immune status of germ-free plants than for plants growing in natural settings. Perhaps not surprisingly, an enormous number of single microbial isolates affect plant growth and immune signaling (Yu et al. 2019). Similarly, the presence of a complex community may suppress the effects of a single potentially deleterious microbe (Finkel et al. 2020). This suggests that the normal physiology and immune function in plants may be established by associations with their microbiota. The effects of individual microbes may be revealed simply by the fact that plants are often studied under highly controlled conditions, and a single microbe is added to observe how the immune thermostat shifts.

Environmental conditions may also constitute key factors in determining plant-microbe interactions. The plant immune status and microbiome community change under a variety of abiotic stresses. For instance, the sorghum and rice rhizosphere microbiomes shift during drought stress (Edwards et al. 2018; $\mathrm{Xu}$ et al. 2018) and temperature affects plant immunity (Alcázar and Parker 2011). Even plant age and development shape the microbiome (Edwards et al. 2018) and affect plant susceptibility to pathogens (Kus et al. 2002). Collectively these observations suggest that the plant symbiosis thermostat is not fixed but, rather, can be fine-tuned over the course of a plant's life by extrinsic and intrinsic signals (Fig. 1C).

Similarly, plant nutrient status has been shown to affect the microbiome composition, mutualistic symbioses, and pathogen susceptibility. Perhaps this is unsurprising, as nutrient exchange or competition drives many symbiotic associations. The Arabidopsis microbiome changes during phosphate stress (Castrillo et al. 2017). Under low nitrogen conditions, legumes secrete larger amounts of flavonoids that, in turn, enhance legume-rhizobia symbioses (Cooper 2004) while they restrict nodulation in the presence of high levels of nitrate (Gibson and Harper 1985). Similarly, mycorrhizal symbiotic relationships are governed by low levels of phosphate (Karandashov and Bucher 2005). Moreover, it has been found that certain pathogenic microbes can undergo a transition to nonpathogenic or even beneficial microbes, depending upon nutritional conditions. For example, in response to low phosphate, the fungus Colletotrichum tofieldiae enters into an endophytic association with Arabidopsis that contributes to enhancing host plant growth (Hiruma et al. 2016). Collectively, these data indicate that plants must integrate nutritional status with immunity to maintain symbiotic homeostasis.

Taken together, these observations suggest that the symbiotic setpoint is not fixed but, rather, could be dialed up or down over 
the life of a plant. Plants might integrate environmental and developmental cues to produce more or fewer antimicrobials in leaves or secrete more nutrients into the rhizosphere (Fig. 1C). We suggest that this symbiotic thermostat could establish a general symbiotic baseline, tuning the associations with broad groups of microbial taxa in leaves or roots. Additionally, the symbiotic thermostat could determine whether receptor-mediated perception of individual microbes warrants the investment of resources necessary to engage with mutualists or ward of pathogens.

\section{ON THE HORIZON: BRIDGING MICROBIAL ECOLOGY AND MOLECULAR BIOLOGY}

As our view of plant-microbe interactions has expanded to encompass plant interactions with thousands of microbiota, so must our view of molecular plant-microbe interactions. Much of our understanding of molecular plant-microbe interactions has been shaped by a small number of model systems. From these genetically tractable systems, we have learned that plants can produce signals to recruit specific microbes while secreting molecules that are toxic to others. We know that plants can perceive microbes or the effects of those microbes on cellular function. Recent research has largely focused on revisiting paradigms of innate immunity or symbiosis in the context of the microbiome. And while well-studied factors like receptors and plant immune hormones do seem to affect microbiome structure (Chen et al. 2020; Lebeis et al. 2015; Rey et al. 2015), in some cases, the effects are relatively less pronounced than in plant-pathogen and rhizobia-legume interactions, suggesting that distinct mechanisms may shape the microbiome. As reverse genetic approaches are limited by our imagination and predictive power, there may be yet undiscovered principles that shape plant-microbiome interactions.

In nature, an individual plant must make thousands of decisions, over its lifetime, whether to engage or attack, and these choices are affected by its age and nutritional status. However, the master program of how plants integrate recognition of microbes with extrinsic and intrinsic cues to create a hospitable environment or restrict microbial growth is largely unknown. Testing multiple immune outputs, such as resistance to herbivores and pathogens and colonization by beneficial microbes (Haney et al. 2018; Vishwanathan et al. 2020), can provide a more wholistic picture of plant immunity. Similarly, direct comparison of germ-free, gnotobiotic, and soil-grown plants can help reveal the baseline immune thermostat setting and how it changes in response to developmental, biotic, and abiotic signals. Coupling work in model systems to reveal mechanisms with multitrophic and ecological studies has the potential to explain how plants navigate interactions with beneficial and pathogenic microbes to establish symbiotic homeostasis.

\section{ACKNOWLEDGMENTS}

We thank members of the Haney Lab for helpful discussion and C. Wiesmann and Y. Song for critical reading of the manuscript.

\section{LITERATURE CITED}

Akiyama, K., and Hayashi, H. 2006. Strigolactones: Chemical signals for fungal symbionts and parasitic weeds in plant roots. Ann. Bot. 97: 925-931.

Alcázar, R., and Parker, J. E. 2011. The impact of temperature on balancing immune responsiveness and growth in Arabidopsis. Trends Plant Sci. 16: 666-675.

Becker, A., Fraysse, N., and Sharypova, L. 2005. Recent advances in studies on structure and symbiosis-related function of rhizobial K-antigens and lipopolysaccharides. Mol. Plant-Microbe Interact. 18:899-905.

Berendsen, R. L., Pieterse, C. M. J., and Bakker, P. A. H. M. 2012. The rhizosphere microbiome and plant health. Trends Plant Sci. 17:478-486.
Berlemont, R., and Martiny, A. C. 2013. Phylogenetic distribution of potential cellulases in bacteria. Appl. Environ. Microbiol. 79:1545-1554. Besserer, A., Puech-Pagès, V., Kiefer, P., Gomez-Roldan, V., Jauneau, A., Roy, S., Portais, J. C., Roux, C., Bécard, G., and Séjalon-Delmas, N. 2006. Strigolactones stimulate arbuscular mycorrhizal fungi by activating mitochondria. PLoS Biol. 4:e226.

Bourassa, D. V., Kannenberg, E. L., Sherrier, D. J., Buhr, R. J., and Carlson, R. W. 2017. The lipopolysaccharide lipid a long-chain fatty acid is important for Rhizobium leguminosarum growth and stress adaptation in free-living and nodule environments. Mol. Plant-Microbe Interact. 30: 161-175.

Bozsoki, Z., Cheng, J., Feng, F., Gysel, K., Vinther, M., Andersen, K. R., Oldroyd, G., Blaise, M., Radutoiu, S., and Stougaard, J. 2017. Receptormediated chitin perception in legume roots is functionally separable from Nod factor perception. Proc. Natl. Acad. Sci. U.S.A. 114: E8118-E8127.

Bozsoki, Z., Gysel, K., Hansen, S. B., Lironi, D., Krönauer, C., Feng, F., de Jong, N., Vinther, M., Kamble, M., Thygesen, M. B., Engholm, E., Kofoed, C., Fort, S., Sullivan, J. T., Ronson, C. W., Jensen, K. J., Blaise, M., Oldroyd, G., Stougaard, J., Andersen, K. R., and Radutoiu, S. 2020. Ligand-recognizing motifs in plant LysM receptors are major determinants of specificity. Science 369:663-670.

Brutus, A., Sicilia, F., Macone, A., Cervone, F., and De Lorenzo, G. 2010. A domain swap approach reveals a role of the plant wall-associated kinase 1 (WAK1) as a receptor of oligogalacturonides. Proc. Natl. Acad. Sci. U.S.A. 107:9452-9457.

Bulgarelli, D., Rott, M., Schlaeppi, K., Ver Loren van Themaat, E., Ahmadinejad, N., Assenza, F., Rauf, P., Huettel, B., Reinhardt, R., Schmelzer, E., Peplies, J., Gloeckner, F. O., Amann, R., Eickhorst, T., and Schulze-Lefert, P. 2012. Revealing structure and assembly cues for Arabidopsis root-inhabiting bacterial microbiota. Nature 488:91-95.

Cai, T., Cai, W., Zhang, J., Zheng, H., Tsou, A. M., Xiao, L., Zhong, Z., and Zhu, J. 2009. Host legume-exuded antimetabolites optimize the symbiotic rhizosphere. Mol. Microbiol. 73:507-517.

Castrillo, G., Teixeira, P. J. P. L., Paredes, S. H., Law, T. F., de Lorenzo, L., Feltcher, M. E., Finkel, O. M., Breakfield, N. W., Mieczkowski, P., Jones, C. D., Paz-Ares, J., and Dangl, J. L. 2017. Root microbiota drive direct integration of phosphate stress and immunity. Nature 543:513-518.

Chen, X., Marszałkowska, M., and Reinhold-Hurek, B. 2020. Jasmonic acid, not salicyclic acid restricts endophytic root colonization of rice. Front. Plant Sci. 10:1758.

Cheng, X., Etalo, D. W., van de Mortel, J. E., Dekkers, E., Nguyen, L., Medema, M. H., and Raaijmakers, J. M. 2017. Genome-wide analysis of bacterial determinants of plant growth promotion and induced systemic resistance by Pseudomonas fluorescens. Environ. Microbiol. 19: 4638-4656.

Choi, H. W., and Klessig, D. F. 2016. DAMPs, MAMPs, and NAMPs in plant innate immunity. BMC Plant Biol. 16:232.

Chuberre, C., Plancot, B., Driouich, A., Moore, J. P., Bardor, M., Gügi, B., and Vicré, M. 2018. Plant immunity is compartmentalized and specialized in roots. Front. Plant Sci. 9:1692.

Cole, B. J., Feltcher, M. E., Waters, R. J., Wetmore, K. M., Mucyn, T. S., Ryan, E. M., Wang, G., Ul-Hasan, S., McDonald, M., Yoshikuni, Y. Malmstrom, R. R., Deutschbauer, A. M., Dangl, J. L., and Visel, A. 2017. Genome-wide identification of bacterial plant colonization genes. PLoS Biol. 15:e2002860.

Cooper, J. E. 2004. Multiple responses of rhizobia to flavonoids during legume root infection. Adv. Bot. Res. 41:1-62

Cope, K. R., Bascaules, A., Irving, T. B., Venkateshwaran, M., Maeda, J., Garcia, K., Rush, T. A., Ma, C., Labbé, J., Jawdy, S., Steigerwald, E., Setzke, J., Fung, E., Schnell, K. G., Wang, Y., Schlief, N., Bücking, H., Strauss, S. H., Maillet, F., Jargeat, P., Bécard, G., Puech-Pagès, V., and Ané, J. M. 2019. The ectomycorrhizal fungus Laccaria bicolor produces lipochitooligosaccharides and uses the common symbiosis pathway to colonize Populus roots. Plant Cell 31:2386-2410.

D'Haeze, W., and Holsters, M. 2002. Nod factor structures, responses, and perception during initiation of nodule development. Glycobiology 12 : 79R-105R.

Denison, R. F., and Kiers, E. T. 2011. Life histories of symbiotic rhizobia and mycorrhizal fungi. Curr. Biol. 21:R775-R785.

Denny, T. P. 1995. Involvement of bacterial polysaccharides in plant pathogenesis. Annu. Rev. Phytopathol. 33:173-197.

Edwards, J. A., Santos-Medellín, C. M., Liechty, Z. S., Nguyen, B., Lurie, E., Eason, S., Phillips, G., and Sundaresan, V. 2018. Compositional shifts in root-associated bacterial and archaeal microbiota track the plant life cycle in field-grown rice. PLoS Biol. 16:e2003862.

Erridge, C., Bennett-Guerrero, E., and Poxton, I. R. 2002. Structure and function of lipopolysaccharides. Microbes Infect. 4:837-851. 
Feng, F., Sun, J., Radhakrishnan, G. V., Lee, T., Bozsóki, Z., Fort, S., Gavrin, A., Gysel, K., Thygesen, M. B., Andersen, K. R., Radutoiu, S., Stougaard, J., and Oldroyd, G. E. D. 2019. A combination of chitooligosaccharide and lipochitooligosaccharide recognition promotes arbuscular mycorrhizal associations in Medicago truncatula. Nat. Commun. 10:5047.

Finkel, O. M., Salas-González, I., Castrillo, G., Conway, J. M., Law, T. F., Teixeira, P. J. P. L., Wilson, E. D., Fitzpatrick, C. R., Jones, C. D., and Dangl, J. L. 2020. A single bacterial genus maintains root growth in a complex microbiome. Nature 587:103-108.

Fisher, R. F., and Long, S. R. 1992. Rhizobium-plant signal exchange. Nature 357:655-660.

Gallo, R. L., and Hooper, L. V. 2012. Epithelial antimicrobial defence of the skin and intestine. Nat. Rev. Immunol. 12:503-516.

Gibelin-Viala, C., Amblard, E., Puech-Pages, V., Bonhomme, M., Garcia, M., Bascaules-Bedin, A., Fliegmann, J., Wen, J., Mysore, K. S., le Signor, C., Jacquet, C., and Gough, C. 2019. The Medicago truncatula LysM receptor-like kinase LYK9 plays a dual role in immunity and the arbuscular mycorrhizal symbiosis. New Phytol. 223:1516-1529.

Gibson, A. H., and Harper, J. E. 1985. Nitrate effect on nodulation of soybean by Bradyrhizobium japonicum. Crop Sci. 25:497-501.

Gough, C., and Cullimore, J. 2011. Lipo-chitooligosaccharide signaling in endosymbiotic plant-microbe interactions. Mol. Plant-Microbe Interact. 24:867-878

Hacquard, S., Garrido-Oter, R., González, A., Spaepen, S., Ackermann, G., Lebeis, S., McHardy, A. C., Dangl, J. L., Knight, R., Ley, R., and Schulze-Lefert, P. 2015. Microbiota and host nutrition across plant and animal kingdoms. Cell Host Microbe 17:603-616.

Hander, T., Fernández-Fernández, Á. D., Kumpf, R. P., Willems, P., Schatowitz, H., Rombaut, D., Staes, A., Nolf, J., Pottie, R., Yao, P., Gonçalves, A., Pavie, B., Boller, T., Gevaert, K., Van Breusegem, F., Bartels, S., and Stael, S. 2019. Damage on plants activates Ca 2+ -dependent metacaspases for release of immunomodulatory peptides. Science 363:eaar7486.

Haney, C. H., Samuel, B. S., Bush, J., and Ausubel, F. M. 2015. Associations with rhizosphere bacteria can confer an adaptive advantage to plants. Nat. Plants 1:15051.

Haney, C. H., Wiesmann, C. L., Shapiro, L. R., Melnyk, R. A., O’Sullivan, L. R., Khorasani, S., Xiao, L., Han, J., Bush, J., Carrillo, J., Pierce, N. E., and Ausubel, F. M. 2018. Rhizosphere-associated Pseudomonas induce systemic resistance to herbivores at the cost of susceptibility to bacterial pathogens. Mol. Ecol. 27:1833-1847.

Harris, J. M., Balint-Kurti, P., Bede, J. C., Day, B., Gold, S., Goss, E. M., Grenville-Briggs, L. J., Jones, K. M., Wang, A., Wang, Y., Mitra, R. M., Sohn, K. H., and Alvarez, M. E. 2020. What are the top 10 unanswered questions in molecular plant-microbe interactions? Mol. Plant-Microbe Interact. 33:1354-1365.

Hartmann, A., Rothballer, M., and Schmid, M. 2008. Lorenz Hiltner, a pioneer in rhizosphere microbial ecology and soil bacteriology research. Plant Soil 312:7-14.

Hayafune, M., Berisio, R., Marchetti, R., Silipo, A., Kayama, M., Desaki, Y., Arima, S., Squeglia, F., Ruggiero, A., Tokuyasu, K., Molinaro, A., Kaku, H., and Shibuya, N. 2014. Chitin-induced activation of immune signaling by the rice receptor $\mathrm{CEBiP}$ relies on a unique sandwich-type dimerization. Proc. Natl. Acad. Sci. U.S.A. 111:E404-E413.

He, J., Zhang, C., Dai, H., Liu, H., Zhang, X., Yang, J., Chen, X., Zhu, Y., Wang, D., Qi, X., Li, W., Wang, Z., An, G., Yu, N., He, Z., Wang, Y. F., Xiao, Y., Zhang, P., and Wang, E. 2019. A LysM receptor heteromer mediates perception of arbuscular mycorrhizal symbiotic signal in rice. Mol. Plant 12:1561-1576.

Hiruma, K., Gerlach, N., Sacristán, S., Nakano, R. T., Hacquard, S., Kracher, B., Neumann, U., Ramírez, D., Bucher, M., O’Connell, R. J., and Schulze-Lefert, P. 2016. Root endophyte Colletotrichum tofieldiae confers plant fitness benefits that are phosphate status dependent. Cell 165:464-474.

Hou, S., Wang, X., Chen, D., Yang, X., Wang, M., Turrà, D., Di Pietro, A., and Zhang, W. 2014. The secreted peptide PIP1 amplifies immunity through receptor-like kinase 7. PLoS Pathog. 10:e1004331.

Huang, A. C., Jiang, T., Liu, Y. X., Bai, Y. C., Reed, J., Qu, B., Goossens, A., Nützmann, H. W., Bai, Y., and Osbourn, A. 2019. A specialized metabolic network selectively modulates Arabidopsis root microbiota. Science 364:eaau6389.

Huang, R., Li, Z., Mao, C., Zhang, H., Sun, Z., Li, H., Huang, C., Feng, Y., Shen, X., Bucher, M., Zhang, Z., Lin, Y., Cao, Y., and Duanmu, D. 2020. Natural variation at OsCERK1 regulates arbuscular mycorrhizal symbiosis in rice. New Phytol. 225:1762-1776.

Jacobowitz, J. R., and Weng, J. K. 2020. Exploring uncharted territories of plant specialized metabolism in the postgenomic era. Annu. Rev. Plant Biol. 71:631-658.
Jewell, J. B., Sowders, J. M., He, R., Willis, M. A., Gang, D. R., and Tanaka, K. 2019. Extracellular ATP shapes a defense-related transcriptome both independently and along with other defense signaling pathways. Plant Physiol. 179:1144-1158.

Jones, J. D. G., and Dangl, J. L. 2006. The plant immune system. Nature 444:323-329.

Jones, K. M., Kobayashi, H., Davies, B. W., Taga, M. E., and Walker, G. C. 2007. How rhizobial symbionts invade plants: The SinorhizobiumMedicago model. Nat. Rev. Microbiol. 5:619-633.

Kadota, Y., Sklenar, J., Derbyshire, P., Stransfeld, L., Asai, S., Ntoukakis, V., Jones, J. D., Shirasu, K., Menke, F., Jones, A., and Zipfel, C. 2014 Direct regulation of the NADPH oxidase RBOHD by the PRRassociated kinase BIK1 during plant immunity. Mol. Cell 54:43-55.

Karandashov, V., and Bucher, M. 2005. Symbiotic phosphate transport in arbuscular mycorrhizas. Trends Plant Sci. 10:22-29.

Kawaharada, Y., Kelly, S., Nielsen, M. W., Hjuler, C. T., Gysel, K., Muszyński, A., Carlson, R. W., Thygesen, M. B., Sandal, N., Asmussen, M. H., Vinther, M., Andersen, S. U., Krusell, L., Thirup, S., Jensen, K. J., Ronson, C. W., Blaise, M., Radutoiu, S., and Stougaard, J. 2015. Receptor-mediated exopolysaccharide perception controls bacterial infection. Nature 523:308-312.

Klauser, D., Desurmont, G. A., Glauser, G., Vallat, A., Flury, P., Boller, T., Turlings, T. C. J., and Bartels, S. 2015. The Arabidopsis Pep-PEPR system is induced by herbivore feeding and contributes to JA-mediated plant defence against herbivory. J. Exp. Bot. 66:5327-5336.

Kus, J. V., Zaton, K., Sarkar, R., and Cameron, R. K. 2002. Age-related resistance in Arabidopsis is a developmentally regulated defense response to Pseudomonas syringae. Plant Cell 14:479-490.

Lebeis, S. L., Paredes, S. H., Lundberg, D. S., Breakfield, N., Gehring, J., McDonald, M., Malfatti, S., Del Rio, T. G., Jones, C. D., Tringe, S. G., and Dangl, J. L. 2015. Salicylic acid modulates colonization of the root microbiome by specific bacterial taxa. Science 349:860-864.

Lee, M. W., Huffaker, A., Crippen, D., Robbins, R. T., and Goggin, F. L. 2018. Plant elicitor peptides promote plant defences against nematodes in soybean. Mol. Plant Pathol. 19:858-869.

Leppyanen, I. V., Shakhnazarova, V. Y., Shtark, O. Y., Vishnevskaya, N. A., Tikhonovich, I. A., and Dolgikh, E. A. 2017. Receptor-like kinase LYK9 in Pisum sativum L. is the CERK1-like receptor that controls both plant immunity and AM symbiosis development. Int. J. Mol. Sci. 19:8.

Li, L., Li, M., Yu, L., Zhou, Z., Liang, X., Liu, Z., Cai, G., Gao, L., Zhang, X., Wang, Y., Chen, S., and Zhou, J. M. 2014. The FLS2-associated kinase BIK1 directly phosphorylates the NADPH oxidase RbohD to control plant immunity. Cell Host Microbe 15:329-338.

Liang, Y., Cao, Y., Tanaka, K., Thibivilliers, S., Wan, J., Choi, J., Kang, C. H., Qiu, J., and Stacey, G. 2013. Nonlegumes respond to rhizobial nod factors by suppressing the innate immune response. Science 341: 1384-1387.

Limpens, E., Franken, C., Smit, P., Willemse, J., Bisseling, T., and Geurts, R. 2003. LysM domain receptor kinases regulating rhizobial Nod factorinduced infection. Science 302:630-633.

Liu, Z., Beskrovnaya, P., Melnyk, R. A., Hossain, S. S., Khorasani, S., O’Sullivan, L. R., Wiesmann, C. L., Bush, J., Richard, J. D., and Haney, C. H. 2018. A genome-wide screen identifies genes in rhizosphereassociated Pseudomonas required to evade plant defenses. MBio 9: e00433-18.

Maillet, F., Poinsot, V., André, O., Puech-Pagès, V., Haouy, A., Gueunier, M., Cromer, L., Giraudet, D., Formey, D., Niebel, A., Martinez, E. A., Driguez, H., Bécard, G., and Dénarié, J. 2011. Fungal lipochitooligosaccharide symbiotic signals in arbuscular mycorrhiza. Nature 469: 58-63.

Millet, Y. A., Danna, C. H., Clay, N. K., Songnuan, W., Simon, M. D., Werck-Reichhart, D., and Ausubel, F. M. 2010. Innate immune responses activated in Arabidopsis roots by microbe-associated molecular patterns. Plant Cell 22:973-990.

Milling, A., Babujee, L., and Allen, C. 2011. Ralstonia solanacearum extracellular polysaccharide is a specific elicitor of defense responses in wilt-resistant tomato plants. PLoS One 6:e15853.

Miyata, K., Kozaki, T., Kouzai, Y., Ozawa, K., Ishii, K., Asamizu, E., Okabe, Y., Umehara, Y., Miyamoto, A., Kobae, Y., Akiyama, K., Kaku, H., Nishizawa, Y., Shibuya, N., and Nakagawa, T. 2014. The bifunctional plant receptor, OsCERK1, regulates both chitin-triggered immunity and arbuscular mycorrhizal symbiosis in rice. Plant Cell Physiol. 55: 1864-1872.

Monteiro, F., and Nishimura, M. T. 2018. Structural, functional, and genomic diversity of plant NLR proteins: An evolved resource for rational engineering of plant immunity. Annu. Rev. Phytopathol. 56: 243-267. 
Müller, D. B., Vogel, C., Bai, Y., and Vorholt, J. A. 2016. The plant microbiota: Systems-level insights and perspectives. Annu. Rev. Genet. 50:211-234.

Ngou, B. P. M., Ahn, H., Ding, P., and Jones, J. D. 2020. Mutual potentiation of plant immunity by cell-surface and intracellular receptors. bioRxiv. $</$ prpt $>$

Owen, C., Patron, N. J., Huang, A., and Osbourn, A. 2017. Harnessing plant metabolic diversity. Curr. Opin. Chem. Biol. 40:24-30.

Pham, A. Q., Cho, S. H., Nguyen, C. T., and Stacey, G. 2020. Arabidopsis lectin receptor kinase $\mathrm{P} 2 \mathrm{~K} 2$ is a second plant receptor for extracellular ATP and contributes to innate immunity. Plant Physiol. 183:1364-1375.

Poncini, L., Wyrsch, I., Dénervaud Tendon, V., Vorley, T., Boller, T., Geldner, N., Métraux, J. P., and Lehmann, S. 2017. In roots of Arabidopsis thaliana, the damage-associated molecular pattern AtPep1 is a stronger elicitor of immune signalling than flg22 or the chitin heptamer. PLoS One 12:e0185808.

Rey, T., Chatterjee, A., Buttay, M., Toulotte, J., and Schornack, S. 2015. Medicago truncatula symbiosis mutants affected in the interaction with a biotrophic root pathogen. New Phytol. 206:497-500.

Robertsen, B. K., Aman, P., Darvill, A. G., McNeil, M., and Albersheim, P. 1981. Host-symbiont interactions: V. The structure of acidic extracellular polysaccharides secreted by Rhizobium leguminosarum and Rhizobium trifolii. Plant Physiol. 67:389-400.

Rudrappa, T., Czymmek, K. J., Paré, P. W., and Bais, H. P. 2008. Rootsecreted malic acid recruits beneficial soil bacteria. Plant Physiol. 148: 1547-1556.

Rush, T. A., Puech-Pagès, V., Bascaules, A., Jargeat, P., Maillet, F., Haouy, A., Maës, A. Q. M., Carriel, C. C., Khokhani, D., Keller-Pearson, M., Tannous, J., Cope, K. R., Garcia, K., Maeda, J., Johnson, C., Kleven, B., Choudhury, Q. J., Labbé, J., Swift, C., O’Malley, M. A., Bok, J. W., Cottaz, S., Fort, S., Poinsot, V., Sussman, M. R., Lefort, C., Nett, J., Keller, N. P., Bécard, G., and Ané, J. M. 2020. Lipochitooligosaccharides as regulatory signals of fungal growth and development. Nat. Commun. 11:3897.

Saile, E., McGarvey, J. A., Schell, M. A., and Denny, T. P. 1997. Role of extracellular polysaccharide and endoglucanase in root invasion and colonization of tomato plants by Ralstonia solanacearum. Phytopathology 87:1264-1271.

Saravanakumar, K., Dou, K., Lu, Z., Wang, X., Li, Y., and Chen, J. 2018. Enhanced biocontrol activity of cellulase from Trichoderma harzianum against Fusarium graminearum through activation of defense-related genes in maize. Physiol. Mol. Plant Pathol. 103:130-136.

Saravanakumar, K., Fan, L., Fu, K., Yu, C., Wang, M., Xia, H., Sun, J., Li, Y., and Chen, J. 2016. Cellulase from Trichoderma harzianum interacts with roots and triggers induced systemic resistance to foliar disease in maize. Sci. Rep. 6:35543.

Sasse, J., Martinoia, E., and Northen, T. 2018. Feed your friends: Do plant exudates shape the root microbiome? Trends Plant Sci. 23:25-41.

Schlaeppi, K., Dombrowski, N., Oter, R. G., Ver Loren van Themaat, E., and Schulze-Lefert, P. 2014. Quantitative divergence of the bacterial root microbiota in Arabidopsis thaliana relatives. Proc. Natl. Acad. Sci. U.S.A. 111:585-592.

Smit, P., Limpens, E., Geurts, R., Fedorova, E., Dolgikh, E., Gough, C., and Bisseling, T. 2007. Medicago LYK3, an entry receptor in rhizobial nodulation factor signaling. Plant Physiol. 145:183-191.

Souza, C. A., Li, S., Lin, A. Z., Boutrot, F., Grossmann, G., Zipfel, C., and Somerville, S. C. 2017. Cellulose-derived oligomers act as damageassociated molecular patterns and trigger defense-like responses. Plant Physiol. 173:2383-2398.

Teixeira, P. J. P., Colaianni, N. R., Fitzpatrick, C. R., and Dangl, J. L. 2019. Beyond pathogens: Microbiota interactions with the plant immune system. Curr. Opin. Microbiol. 49:7-17.

Vishwanathan, K., Zienkiewicz, K., Liu, Y., Janz, D., Feussner, I., Polle, A., and Haney, C. H. 2020. Ectomycorrhizal fungi induce systemic resistance against insects on a nonmycorrhizal plant in a CERK1dependent manner. New Phytol. 228:728-740.

Voges, M. J. E. E. E., Bai, Y., Schulze-Lefert, P., and Sattely, E. S. 2019. Plant-derived coumarins shape the composition of an Arabidopsis synthetic root microbiome. Proc. Natl. Acad. Sci. U.S.A. 116: 12558-12565.

Xu, L., Naylor, D., Dong, Z., Simmons, T., Pierroz, G., Hixson, K. K., Kim, Y. M., Zink, E. M., Engbrecht, K. M., Wang, Y., Gao, C., DeGraaf, S., Madera, M. A., Sievert, J. A., Hollingsworth, J., Birdseye, D., Scheller, H. V., Hutmacher, R., Dahlberg, J., Jansson, C., Taylor, J. W., Lemaux, P. G., and Coleman-Derr, D. 2018. Drought delays development of the sorghum root microbiome and enriches for monoderm bacteria. Proc. Natl. Acad. Sci. U.S.A. 115:E4284-E4293.

Yamaguchi, Y., Huffaker, A., Bryan, A. C., Tax, F. E., and Ryan, C. A. 2010. PEPR2 is a second receptor for the Pep1 and Pep2 peptides and contributes to defense responses in Arabidopsis. Plant Cell 22:508-522.

Yu, K., Liu, Y., Tichelaar, R., Savant, N., Lagendijk, E., van Kuijk, S. J. L., Stringlis, I. A., van Dijken, A. J. H., Pieterse, C. M. J., Bakker, P. A. H. M., Haney, C. H., and Berendsen, R. L. 2019. Rhizosphereassociated Pseudomonas suppress local root immune responses by gluconic acid-mediated lowering of environmental pH. Curr. Biol. 29: 3913-3920.e4.

Yuan, M., Jiang, Z., Bi, G., Nomura, K., Liu, M., He, S. Y., Zhou, J.-M., and Xin, X.-F. 2020. Pattern-recognition receptors are required for NLRmediated plant immunity. bioRxiv. $<$ prpt $>$

Zhang, L., and Gleason, C. 2020. Enhancing potato resistance against rootknot nematodes using a plant-defence elicitor delivered by bacteria. Nat. Plants 6:625-629.

Zhou, F., Emonet, A., Dénervaud Tendon, V., Marhavy, P., Wu, D., Lahaye, T., and Geldner, N. 2020. Co-incidence of damage and microbial patterns controls localized immune responses in roots. Cell 180:440-453. e18.

Zipfel, C. 2014. Plant pattern-recognition receptors. Trends Immunol. 35: 345-351.

Zipfel, C., and Oldroyd, G. E. D. 2017. Plant signalling in symbiosis and immunity. Nature 543:328-336. 